\title{
Incidence of sudden cardiac death in adults with end-stage renal disease: a systematic review and meta-analysis
}

\author{
Sharanya Ramesh", Ann Zalucky ${ }^{1}$, Brenda R. Hemmelgarnn ${ }^{2,3}$, Derek J. Roberts ${ }^{3,4}$, Sofia B. Ahmed ${ }^{1,5}$,
} Stephen B. Wilton ${ }^{1,5}$ and Min Jun ${ }^{2,3,6^{*}}$

\begin{abstract}
Background: Although sudden cardiac death (SCD) is recognized as a distinct cause of death in patients with end stage renal disease (ESRD), its incidence has not been well summarized.

Methods: We performed a systematic review and meta-analysis of the literature based on a protocol developed $a$ priori. We searched MEDLINE and EMBASE (inception to March 2015) for randomized controlled trials and cohort studies reporting the incidence of SCD in adult patients with ESRD on hemodialysis or peritoneal dialysis. We collected data on number of SCD as well as the definition of SCD for each individual study. A random-effects model was used to summarize the incidence of SCD. We conducted subgroup analyses to explore sources of heterogeneity.

Results: Forty two studies ( $n=80,382$ patients) were included in the meta-analysis. The incidence of SCD among adults with ESRD ranged from 0.4 to 10.04 deaths per 100 person-years. The definitions and assessment of SCD varied across the included studies. There was evidence of significant heterogeneity $\left(I^{2}=98 ; p<0.001\right)$, which was not explained by subgroup analyses stratified by mean age, proportion of hypertensive or diabetic patients, follow-up time, study size, or type of cohort studied.

Conclusion: Current estimates of the incidence of SCD among adults with ESRD vary widely. There is a need for further studies to more accurately estimate the incidence of SCD in patients with ESRD.
\end{abstract}

Keywords: Sudden cardiac death, End stage renal disease, Incidence, Systematic review

\section{Background}

The rising prevalence of end stage renal disease (ESRD) is a global public health concern [1-3]. Adults with ESRD have mortality rates up to 30 -fold higher than the general population, with cardiovascular disease the major cause of death, accounting for approximately $38 \%$ of all deaths among patients receiving chronic dialysis [4]. Sudden cardiac death (SCD), typically defined as death due to cardiac arrest occurring suddenly and within $1 \mathrm{~h}$ of witnessed symptom onset (or occurring

\footnotetext{
* Correspondence: mjun@ucalgary.ca

${ }^{2}$ Department of Medicine, Division of Nephrology, University of Calgary, Health Sciences Building, Room G233, 3330 Hospital Drive NW, Calgary, AB T2N 4N1, Canada

${ }^{3}$ Department of Community Health Sciences, University of Calgary, Calgary, AB, Canada

Full list of author information is available at the end of the article
}

within $24 \mathrm{~h}$ since last the patient had been known to be well), is responsible for the majority of cardiovascularrelated deaths in patients with ESRD with studies reporting that up to $25 \%$ of all deaths in this high-risk population is attributable to SCD [5]. However, there is substantial inconsistency in the definition of SCD, leading to wide variations in the reported SCD rates among individuals with ESRD [6]. Narrative reviews have attempted to summarize SCD rates in patients with ESRD $[5,7,8]$, however, these reviews have not been systematically conducted, and their primary purpose was to summarize possible causes and mechanisms of SCD. We therefore sought to conduct a systematic review and meta-analysis of randomized trials and cohort studies to determine the incidence of SCD in adults with ESRD. 


\section{Methods}

\section{Data sources and searches}

We performed a systematic review of the literature based on a protocol developed a priori in accordance with recommendations from the Meta-analysis of Observational Studies in Epidemiology and Preferred Reporting Items for Systematic Reviews and Meta-analyses statements [9].

We identified relevant studies by searching Ovid MEDLINE (from 1950 to March 2015) and EMBASE (from 1980 to March 2015) without language restrictions. All relevant text words and Medical Subject Heading (MeSH)/Emtree terms for chronic kidney disease ("Renal Insufficiency Chronic", "Kidney Failure", "Kidney Diseases", "Renal Replacement Therapy", "Uremia", "Dialysis", "Hemodialysis", "Hemofiltration", "Peritoneal Dialysis" or "Predialysis") and SCD ("Heart Arrest" or "Sudden Cardiac Death" or "Sudden Arrhythmic Death") were combined separately using the "OR" Boolean operator. These two search themes were then combined using the Boolean "AND" operator (Additional file 1). To identify additional relevant studies, we manually screened reference lists from identified studies and contacted field experts.

\section{Study selection}

Two independent reviewers (SR and AZ) screened all abstracts identified by the search using a standardized approach to determine relevant articles for full-text review. All cohort studies and randomized controlled trials conducted in adults (age $\geq 18$ years) with ESRD receiving dialysis (hemodialysis or peritoneal dialysis) and reporting on $\geq 5$ events of SCD were eligible for inclusion in the systematic review. Studies examining the incidence of SCD in transplant recipients were excluded. Any disagreement in study inclusion was resolved by a third reviewer $(\mathrm{MJ})$.

\section{Data extraction}

A standardized data extraction spreadsheet was developed and used to abstract data on baseline participant characteristics including age, sex, body mass index, systolic and diastolic blood pressure, proportion of patients with diabetes, hypertension, myocardial infarction, coronary artery disease, current smokers, alcohol intake, and ethnicity, as well as follow-up duration, and SCD (as defined by authors).

\section{Study quality assessment}

Study quality was judged based on standard criteria relevant to systematic reviews of cohort studies [10] and the Cochrane Risk of Bias for randomized controlled trials. For observational studies, the criteria assessed were patient attrition, acknowledgement of sources of funding, clear description of SCD, clear description of study participant characteristics, number of participants at each stage of study and reasons for ineligibility, proportion of eligible participants described, evidence of consecutive or random sampling, clear descriptions of inclusion criteria and sources and methods of participant selection and study setting, and locations and dates for recruitment. For randomized trials, study quality was judged by proper conduct of randomization, treatment allocation concealment, use of intention-to-treat, blinding of participants and outcome assessment, and evidence for incomplete or selective reporting of outcome. For each criterion, a study was considered to be at low risk if the information for the assessment was provided and there was sufficient evidence to fulfill criteria requirement. A study was considered at medium risk if there was evidence to suggest that part of the criteria requirement was completed, however, not sufficiently to reduce bias. A study was considered to be high risk if no information was provided or if no information regarding a failure to meet criteria requirements was provided.

\section{Outcome}

We collected data on the number of SCD events as well as the definition of SCD for each individual study.

\section{Data synthesis and analysis}

The incidence of SCD in each of the individual studies and the corresponding Wilson score $95 \%$ confidence intervals (CIs) for binomial data were calculated [11]. In calculating the incidence, the total number of patients at risk was multiplied by the mean or median follow up in each study to obtain the denominator (person-years of follow-up) and the number of SCD events contributed to the numerator. Incidence rates were expressed as per 100 person-years.

Summary estimates of incidence and incidence rates of SCD were obtained using a DerSimonian and Laird random effects model [12]. The percentage of variability across studies due to heterogeneity beyond chance was estimated using $\mathrm{I}^{2}$ statistics [13] and Cochran's Q tests of homogeneity. We explored sources of heterogeneity across the estimates of SCD cumulative incidence using univariate meta-regression [13] and subgroup analysis by comparing summary results obtained from subsets of studies dichotomized based on study mean age, proportion of hypertensive patients, proportion of diabetic patients, follow-up duration, study mean BMI, study mean systolic blood pressure, study mean diastolic blood pressure, method of SCD ascertainment (chart review vs. rigorous assessment), and type of cohort (general population vs. selective). We classified studies as a general population cohort if the study encompassed a wide spectrum of patients on dialysis with a broad eligibility criterion and as a selective cohort if the study aimed to 
capture a subset of patients on dialysis. A two-sided $p$-value $<0.05$ was considered statistically significant for all analyses. All statistical analyses were performed with Stata/IC version 12.0 (Stata Corp., College Station, TX, USA).

\section{Results}

\section{Study and included patient characteristics}

The literature search yielded a total of 3,854 citations, of which 488 qualified for full text review (Fig. 1). The final analysis included 42 studies with 80,382 patients with ESRD reporting on 8,574 SCD events. The characteristics of the studies included in the systematic review are shown in Additional file 2. Of the 42 studies, 40 were cohort studies, 1 was a randomized controlled trial, and 2 were observational analyses of randomized controlled trials. 14 were from Asia [14-27], 17 from Europe [28-44], 7 from North America [30, 45-52], 1 from Oceania [53], 2 from South America [54, 55], and 1 international study conducted across centers in Europe, North America and Oceania [56]. The studies were published between 1985 and 2014 and the number of patients enrolled ranged from 22 to 37,765. Most studies were conducted in hemodialysis patients (71 \%) with only two enrolling specifically peritoneal dialysis patients $[27,38]$. The mean age of patients ranged from 44 to 71 years and the proportion of males ranged from 48 to $83 \%$. Data on comorbidities were generally limited. The proportion of patients with hypertension across the included studies ranged between 5 and $91 \%$ while those with diabetes ranged between 6 and $100 \%$.

\section{Study quality}

The assessment of the risk of bias in the included studies is summarized in Fig. 2. Thirty-eight studies provided information regarding the setting, locations and dates of studies [14-19, 21-37, 40-43, 45-48, 51-57]. Furthermore, 34 of 42 studies (81 \%) had clearly defined eligibility criteria $[14,15,17-19,21,24-31,33-38,40-44,46-48$, 51-57]. Twenty one (50 \%) studies had a low risk of selection bias based on their random or consecutive sampling method [15, 21, 24, 26, 29-31, 34-36, 41-43, 46, 48, 51, $52,54,55,57]$. The eligibility criteria and participant rate were described adequately in 29 studies (69\%) [14, 15, 19, 21, 24-31, 33-35, 37, 41-44, 46-48, 51-55, 57], and 15 studies $(36 \%)[19,21,24,28-31,35,37,42,44,47$,

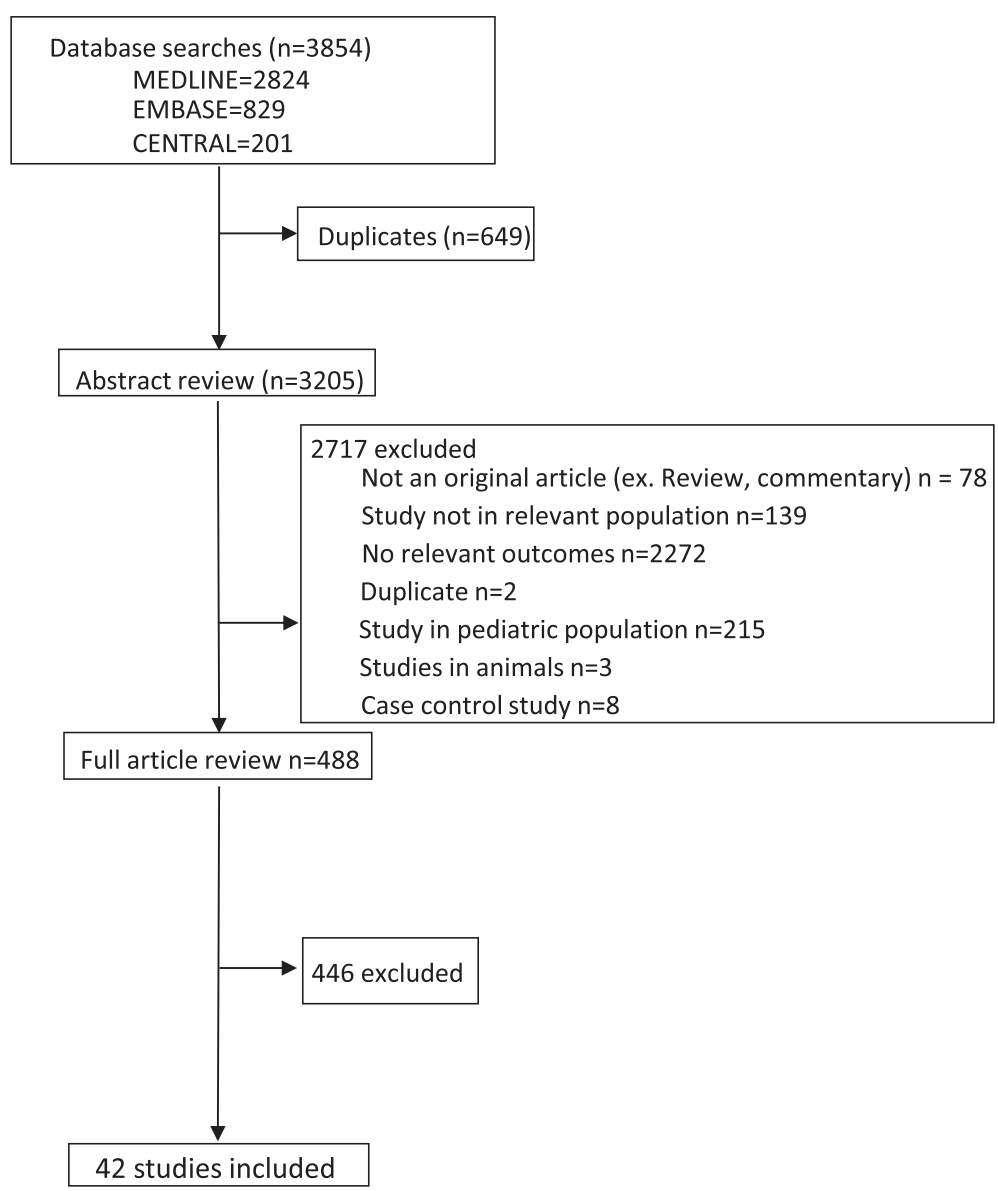

Fig. 1 PRISMA flow diagram showing the identification process for eligible studies 


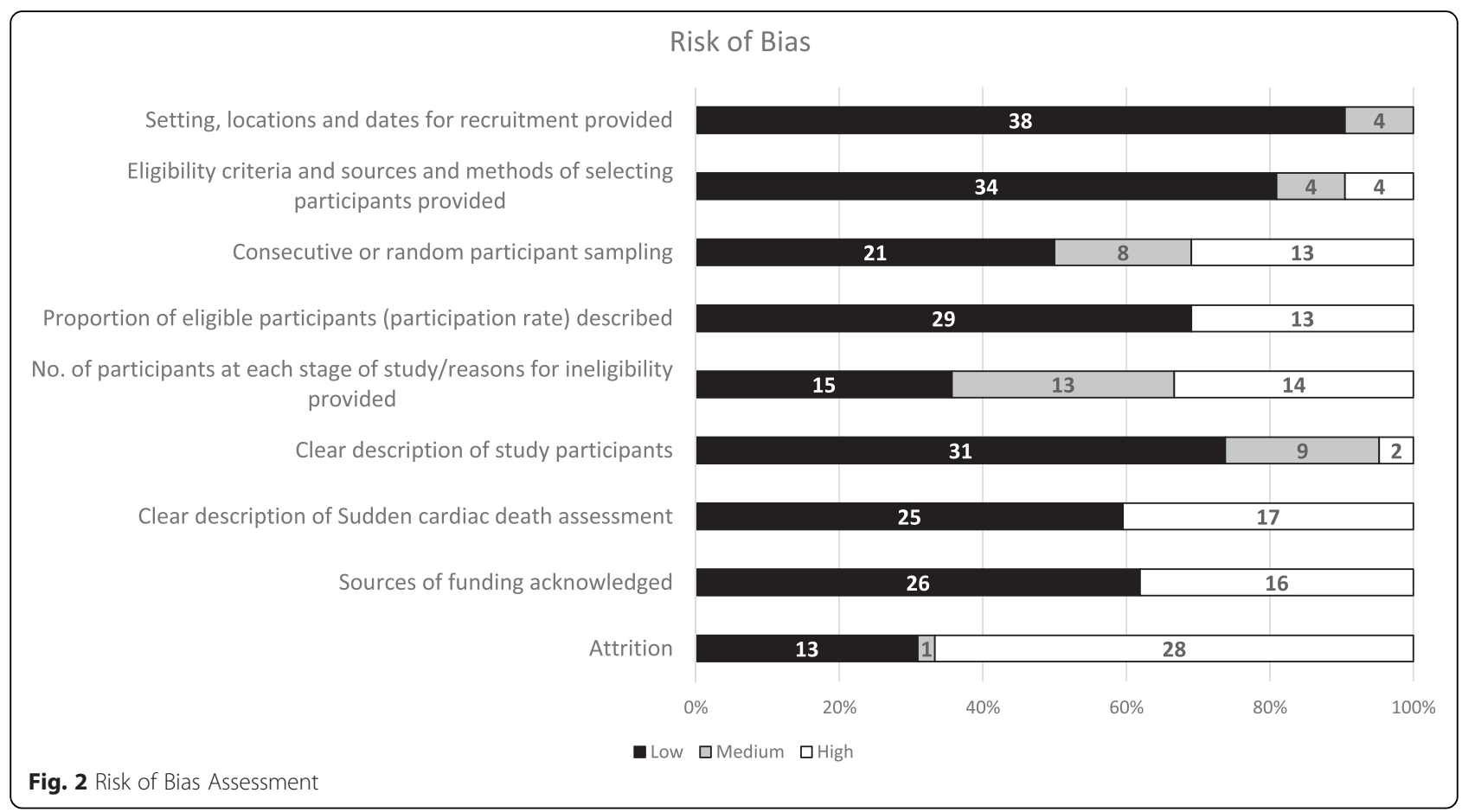

$48,54,55]$ described the flow of participants and reasons of ineligibility. Thirty one studies (74 \%) provided a clear description of the characteristics of the included participants $[14,15,17-19,21,24,26-35$, $37,41-46,48,51-56]$ and 24 studies (57 \%) appropriately defined sudden cardiac death $[15,17,19-21,23$, 27, 29, 31, 33-37, 41, 42, 46, 51-57]. Additionally, 26 and 13 studies acknowledged the sources of funding $[14,16,18,21,23,24,26-29,31-34,36,38,41-43$, $45,47,51-54,56]$ and attrition [17-19, 21, 24, 27, $29,31,35,37,48,51,53,55]$, respectively.

Of the three studies with data from clinical trials, the overall risk of bias was low. Although only one study provided details about allocation bias [32], the risk of bias associated with blinding, randomization and selective outcome reporting was low.

\section{Definition of SCD and SCD assessment}

The definition of SCD varied among the included studies. Twenty-six (of which 3 were from trials) of the 43 studies provided a definition for SCD [15, 17-21, 23, 27, 29, 31, 32, 34-37, 41, 42, 46, 48, 51-54, 56, 57]. Seventeen studies included time in their definition of SCD [15, 17, 19-21, 23, 27, 29, 31, 34-36, 41, 42, 46, 52, 54]. Eight studies included hyperkalemia, cardiac arrhythmia and cardiac arrest in their definitions of SCD $[21,32,44,48,51-53,56]$ and one study broadened their definition to include any unwitnessed and unexpected cardiac death [52]. The most common definitions of SCD were "death occurring within an hour of symptom onset with no clinical support for another cause" $(n=12 ; 28 \%)$ where SCD incidence ranged from 0.76 to 7.09 SCD events per 100 person years and "death occurring within $24 \mathrm{~h}$ of symptom onset with no clinical support for another cause" ( $n=5 ; 12 \%)$ where SCD incidence ranged from 2.09 to 3.38 SCD events per 100 person-years.

Similar to the variability in the definition of cardiac death, the rigor of assessment of SCD varied among the included studies. Seven studies did not provide any information about the assessment of SCD [14, 23, 33, 38, 43, 47, 49]. Nineteen studies assessed SCD using death certificates and chart reviews $[15,16,18,20,24,25$, 28-32, 34-36, 41, 44, 48, 52, 57] and 16 studies assessed SCD using a more rigorous method, i.e., using blinded assessment, physician interviews, coroner's report and/or witness interviews $[17,19,21,22,24,26,27,35$, $37,40,42,45,46,50,51,53-56]$.

\section{Estimated incidence rates of sudden cardiac death}

A total of 8,574 SCD events occurred in 80,382 participants over a follow-up that ranged between 1.5 and 10 years. The estimated incidence rate of SCD among adults with ESRD ranged from 0.4 to 10.04 deaths per 100 person-years (Fig. 3). We observed evidence of significant heterogeneity across the included studies $\left(\mathrm{I}^{2}=98 \%, p<0.001\right)$ and therefore did not calculate a summative estimate of the incidence rates. Additionally, the incidence rates were not significantly different between the two most common definitions of $\operatorname{SCD}(p=0.1)$. The incidence rate in studies that included time in their 


\begin{tabular}{|c|c|c|c|}
\hline \multicolumn{3}{|l|}{ Study } & \multirow{2}{*}{$\begin{array}{l}\text { ES }(95 \% \mathrm{Cl}) \\
3.10(0.84,5.36)\end{array}$} \\
\hline Alam et al. (2013) & $7 / 133$ & $\longrightarrow$ & \\
\hline Amabile et al. (2012) & $5 / 81$ & $\rightarrow$ & $1.47(0.19,2.75)$ \\
\hline Beaubien et al. (2002) & $21 / 147$ & $\leadsto$ & $1.59(0.91,2.26)$ \\
\hline Blacher et al. (2003) & $12 / 242$ & $\bullet$ & $0.76(0.33,1.19)$ \\
\hline Cashion et al. (2005) & $5 / 53$ & & $4.72(0.68,8.75)$ \\
\hline De Bie et al. (2013) & $18 / 277$ & - & $3.09(1.69,4.50)$ \\
\hline De Lima et al. (1995) & $5 / 74$ & $\rightarrow$ & $1.33(0.17,2.49)$ \\
\hline De Lima et al. (2011) & $44 / 1139$ & $\rightarrow$ & $1.93(1.37,2.50)$ \\
\hline Drechsler et al. (2011) & $27 / 762$ & 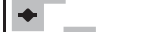 & $1.01(0.63,1.39)$ \\
\hline Drechsler et al. (2012) & $160 / 1255$ & $\bullet$ & $3.22(2.73,3.71)$ \\
\hline Foley et al. (1995) & $38 / 433$ & & $2.56(1.76,3.37)$ \\
\hline Fukuta et al. (2003) & 9/81 & & $3.10(1.11,5.10)$ \\
\hline Ganesh et al. (2001) & $1111 / 12833$ & $\bullet$ & $4.33(4.08,4.58)$ \\
\hline Genovesi et al. (2009) & $12 / 122$ & & $2.24(1.47,3.01)$ \\
\hline Genovesi et al. (2013) & $32 / 476$ & & $2.59(1.14,4.03)$ \\
\hline Hayano et al. (1999) & $11 / 31$ & & $7.10(3.05,11.14)$ \\
\hline Iliou et al. (2003) & $13 / 258$ & & $2.52(1.17,3.87)$ \\
\hline Jadoul et al. (2012) & $2442 / 37765$ & - & $4.07(3.91,4.22)$ \\
\hline Johansson et al. (2007) & $15 / 216$ & $\rightarrow$ & $2.04(1.02,3.07)$ \\
\hline Kircelli et al. (2010) & $6 / 243$ & $\rightarrow$ & $0.81(0.16,1.45)$ \\
\hline Koch et al. (1993) & $20 / 196$ & $\rightarrow$ & $2.15(1.22,3.08)$ \\
\hline Krishnasamy et al. (2013) & $3778 / 14636$ & - & $2.87(2.78,2.96)$ \\
\hline Kruzan et al. (2014) & $75 / 503$ & $-\infty$ & $4.26(3.32,5.20)$ \\
\hline Li et al. (2014) & $12 / 278$ & $\rightarrow$ & $2.40(1.06,3.74)$ \\
\hline Matsue et al. (2013) & $30 / 316$ & $\rightarrow$ & $2.16(1.39,2.92)$ \\
\hline Matsumoto et al. (2014) & $5 / 152$ & $\rightarrow$ & $1.10(0.14,2.05)$ \\
\hline Moroi et al. (2013) & $20 / 677$ & $\bullet$ & $0.98(0.56,1.41)$ \\
\hline Nakamura et al. (2005) & $5 / 48$ & - & $3.38(0.47,6.29)$ \\
\hline Nishimura et al. (2011) & $17 / 155$ & $\rightarrow$ & $2.15(1.14,3.16)$ \\
\hline Ohsawa et al. (2012) & $99 / 1195$ & $\bullet$ & $2.09(1.68,2.50)$ \\
\hline Paoletti et al. (2004) & $16 / 123$ & $\rightarrow$ & $1.30(0.67,1.93)$ \\
\hline Ritz et al. (1985) & $55 / 365$ & & $10.04(7.52,12.55)$ \\
\hline Scialla et al. (2011) & $119 / 824$ & $\leadsto$ & $4.51(3.72,5.30)$ \\
\hline Shoji et al. (2004) & $12 / 242$ & 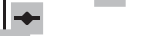 & $0.98(0.43,1.52)$ \\
\hline Takahashi et al. (2013) & $22 / 1290$ & $\bullet$ & $0.40(0.23,0.57)$ \\
\hline Tanaka et al. (2012) & $5 / 22$ & & $6.67(1.02,12.31)$ \\
\hline Tangri et al. (2011) & $181 / 1747$ & 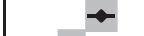 & $4.14(3.55,4.73)$ \\
\hline Terazawa et al. (2012) & $11 / 125$ & - & $2.87(1.20,4.54)$ \\
\hline Vazquez et al. (2014) & $59 / 285$ & & $6.22(4.69,7.76)$ \\
\hline Voroneanu et al. (2014) & $6 / 98$ & $\rightarrow$ & $2.45(0.51,4.38)$ \\
\hline Wang et al. (2010) & $28 / 230$ & $\rightarrow$ & $2.43(1.54,3.33)$ \\
\hline Zocalli et al. (2001) & $6 / 254$ & $\rightarrow$ & $0.98(0.20,1.76)$ \\
\hline Overall $(\mathrm{I}-$ squared $=97.6 \%$ & & & $2.57(2.10,3.04)$ \\
\hline
\end{tabular}

Fig. 3 Estimated incidence rate

definition was 2.98 SCD per 100 person-years (95\% CI: 2.87-3.11) and was 2.66 SCD per 100 person-years $95 \%$ CI: 2.57-2.76) for studies that included hyperkalemia in their definition.

\section{Subgroup analysis}

Studies with greater than or equal to $32 \%$ of subjects with diabetes had a greater incidence of SCD compared to studies with less than $32 \%$ of subjects with diabetes $(p=0.05$; Fig. 4). Studies that had greater than or equal to 3.4 years of follow up had a lower estimated incidence rate of SCD compared to studies with less than 3.4 years of follow up ( $p=0.04$; Fig. 4).

\section{Discussion}

Our quantitative review of randomized controlled trials and cohort studies including over 81,000 patients with ESRD on dialysis shows that the reported incidence of
SCD in ESRD varies widely, ranging from 0.4 to 10.04 deaths per 100 person-years. In addition, there is a lack of standardization in the definitions of SCD in ESRD as well as the methods of its assessment.

The lack of standardization and variability in SCD definition has previously been identified in the general population [58]. We have identified similar heterogeneity in SCD definition among dialysis patients as well as inconsistencies in adjudication methods.

The current lack of a standardized definition of SCD in ESRD, in addition to the varied methods of its assessment, are likely to be major contributors to the wide range of estimates reported. As was the case with the systematic review conducted in the general population [58], studies with the primary aim of determining the incidence of SCD was lacking as we observed only 1 study specifically focused on the assessment of the incidence of SCD. 


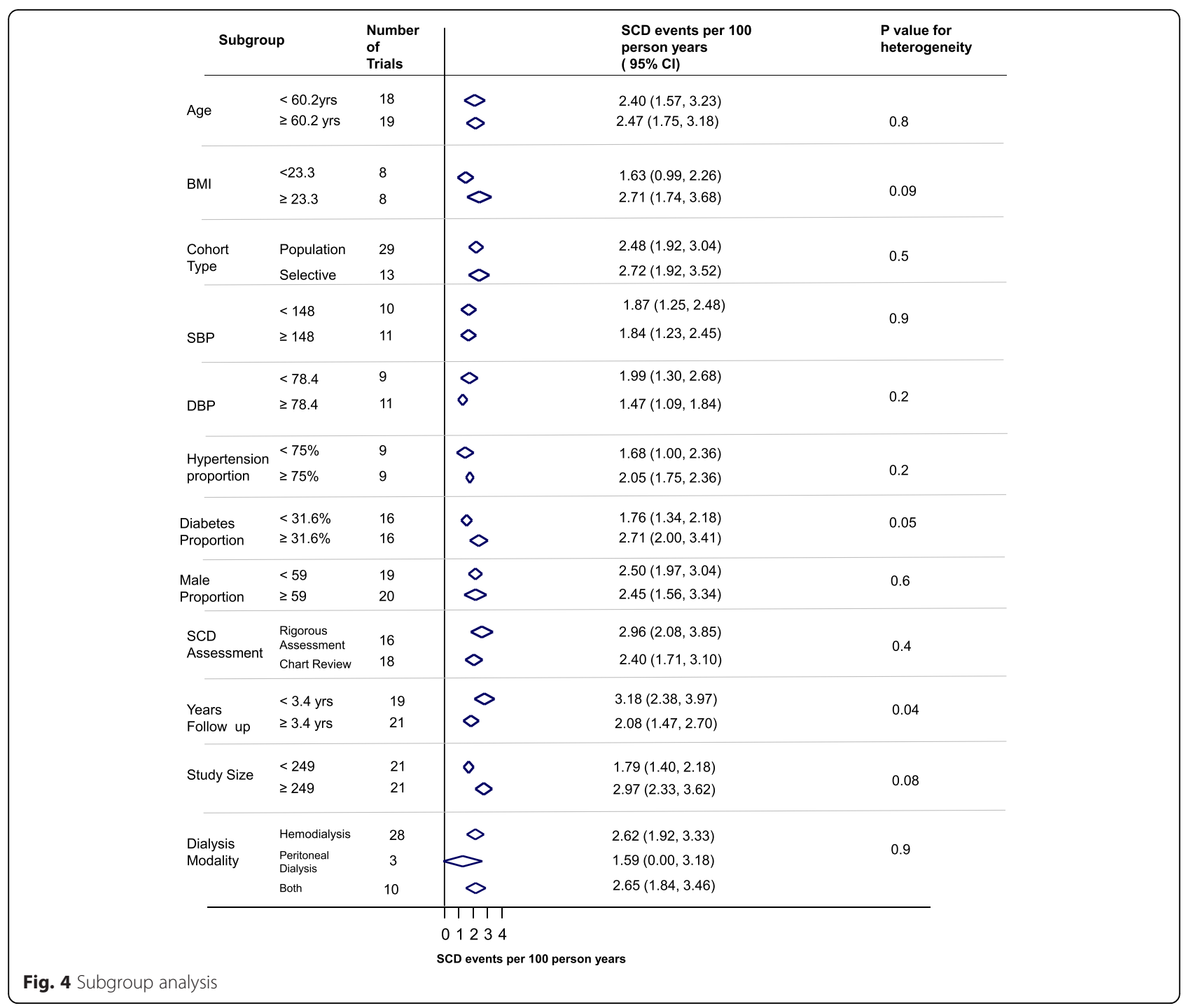

Large, population-based renal registries such as the United States Renal Data System (USRDS) and the Australia and New Zealand Dialysis and Transplant (ANZDATA) Registry have reported causes of death, including SCD (cardiac arrest), among dialysis patients. While large-scale multicenter studies are currently needed to further validate results derived from these registries, it is reassuring that our results are largely consistent with registry-based SCD the incidence rate reported by the United States Renal Data System (USRDS) (4.3 events per 100 person-years) [59] and the proportion of cardiac death as reported by The Australia and New Zealand Dialysis and Transplant Registry (ANZDATA) (2.3\%) [60].

Our subgroup analysis found that studies with higher proportion of patients with diabetes reported a higher incidence of SCD. Diabetes has been found to increase SCD risk in both healthy subjects and subjects with CKD. Indeed, the 'Paris Prospective Study I', a 23-year long prospective study of 7,000 males suggested that diabetes was associated with a SCD risk ratio of 2.2, higher than any other factor evaluated in the study [61]. Moreover, an analysis of 400 SCD cases by Karnik et al. in a cohort of hemodialysis patients found that patients who died of SCD were more likely to have diabetes compared to patients who died of other causes (61.8 vs. $46.8 \%)$ [62]. Finally, we found that studies with a longer followup time had a higher estimated incidence of SCD compared to those with a shorter follow-up time. While there were no apparent differences in comorbidities or SCD assessment between these studies, one possible explanation could be a higher chance of loss to follow-up in longer studies compared to shorter studies. This, however, cannot be confirmed as many studies did not report on attrition.

Our systematic review has limitations. Our analysis was restricted by the overall paucity of studies reporting 
on SCD incidence and was based on published studylevel data. With only two studies reporting incidence rates, we were limited in our ability to assess the incidence of SCD in patients on dialysis. We were limited in our ability to explore the effects of race on SCD incidence rate through subgroup analyses as only 6 of the 43 included studies reported on race of the subjects. Another limitation of this study is the lack of inclusion of all large registry data. While the primary purpose of this study was to summarize data from published studies, large national registry databases provide important information with regards to SCD in the dialysis population and future studies should focus on verifying and improving the accuracy of these databases with large validations studies designed to assess the incidence of SCD in patients with ESRD. This study highlights the need for the standardization of SCD definition and ascertainment, and for larger multicenter studies that aim to determine the incidence of SCD in this high risk population.

\section{Conclusion}

The reported incidence of SCD in patients with ESRD varies widely and studies specifically designed to determine the incidence of SCD in adults with ESRD are limited. As SCD remains a major concern in the patients with ESRD our findings emphasize that further investigation to determine the incidence of SCD within this patient population is needed.

\section{Additional files}

Additional file 1: Includes details regarding the search strategy used for the systematic review. (DOC $28 \mathrm{~kb}$ )

Additional file 2: Includes a table describing the characteristics of the included studies. (DOC $96 \mathrm{~kb}$ )

\section{Abbreviations}

ESRD, end stage renal disease; SCD, sudden cardiac death

\section{Acknowledgements}

SR is supported by the William Davies Scholarship and the Roy and Vi Baay Chair of Kidney Research Student Scholarship. AZ is supported by the American Society of Nephrology. SBW is supported by a grant from St. Jude Medical and Alberta Health Services. BH and SA are supported by a joint initiative between Alberta Health and Wellness and the Universities of Alberta and Calgary. DJR is funded by an Alberta Innovates-Health Solutions Clinician Fellowship Award, a Knowledge Translation Canada Strategic Funding in Health Research Fellowship, and the Canadian Institutes of Health Research. SA is supported by Alberta Innovates - Health Solutions. MJ is supported by postdoctoral fellowships from the Canadian Institutes of Health Research and Alberta Innovates Health Solutions, and an early career fellowship from the National Health and Medical Research Council of Australia.

\section{Funding}

This study did not have a specific funding source.

\section{Availability of data and materials}

All datasets analyzed in this systematic review are referenced in the manuscript and its Additional files 1 and 2 .

\section{Authors' contributions}

SR was involved in conception and study design, collection and assembly of data, data analysis and interpretation, manuscript writing and final approval of manuscript. AZ was involved in conception and study design, collection and assembly of data, data analysis and interpretation and final approval of manuscript. BH was involved in conception and study design, data interpretation and final approval of manuscript. DR was involved in data analysis and interpretation and final approval of manuscript. SA was involved in data interpretation and final approval of manuscript. SB was involved in data interpretation and final approval of manuscript. MJ was involved in conception and study design, collection and assembly of data, data analysis and interpretation, and final approval of manuscript.

\section{Competing interests}

The authors declare that they have no competing interests.

\section{Consent for publication}

Not applicable.

\section{Ethical approval and consent to participate}

Not applicable.

\section{Author details}

${ }^{1}$ Cumming School of Medicine, University of Calgary, Calgary, AB, Canada. ${ }^{2}$ Department of Medicine, Division of Nephrology, University of Calgary, Health Sciences Building, Room G233, 3330 Hospital Drive NW, Calgary, AB T2N 4N1, Canada. ${ }^{3}$ Department of Community Health Sciences, University of Calgary, Calgary, AB, Canada. ${ }^{4}$ Department of Surgery, University of Calgary and the Foothills Medical Centre, Calgary, AB, Canada. ${ }^{5}$ Libin Cardiovascular Institute of Alberta, Calgary, AB, Canada. ${ }^{6}$ The George Institute for Global Health, The University of Sydney, Sydney, Australia.

Received: 18 November 2015 Accepted: 14 June 2016

Published online: 11 July 2016

\section{References}

1. Gilbertson DT, Liu J, Xue JL, Louis TA, Solid CA, Ebben JP, Collins AJ. Projecting the number of patients with end-stage renal disease in the United States to the year 2015. J Am Soc Nephrol. 2005;16(12):3736-41.

2. Ligot AP. CMAJ on the Web. Can Med Assoc J. 2003;168(12):1528-8.

3. Hallan SI, Coresh J, Astor BC, Åsberg A, Powe NR, Romundstad S, Hallan HA, Lydersen S, Holmen J. International comparison of the relationship of chronic kidney disease prevalence and ESRD risk. J Am Soc Nephrol. 2006;17(8):2275-84.

4. System URD. USRDS 2013 Annual Data Report: Atlas of Chronic Kidney Disease and end-Stage Renal Disease in the United States. Bethesda: National Institutes of Health, National Institute of Diabetes and Digestive and Kidney Diseases; 2012

5. Shamseddin MK, Parfrey PS. Sudden cardiac death in chronic kidney disease: epidemiology and prevention. Nat Rev Nephrol. 2011;7(3):145-54.

6. Fishman Gl, Chugh SS, DiMarco JP, Albert CM, Anderson ME, Bonow RO, Buxton $A E$, Chen PS, Estes M, Jouven X. Sudden cardiac death prediction and prevention report from a National Heart, Lung, and Blood Institute and Heart Rhythm Society workshop. Circulation. 2010;122(22):2335-48.

7. Pun PH, Middleton JP. Sudden cardiac death in hemodialysis patients: a comprehensive care approach to reduce risk. Blood Purif. 2012;33(1-3):183-9.

8. Green D, Roberts PR, New DI, Kalra PA. Sudden cardiac death in hemodialysis patients: an in-depth review. Am J Kidney Dis. 2011;57(6):921-9.

9. Moher D, Liberati A, Tetzlaff J, Altman DG. Preferred reporting items for systematic reviews and meta-analyses: the PRISMA statement. Ann Intern Med. 2009;151(4):264-9.

10. Hayden JA, Côté $P$, Bombardier C. Evaluation of the quality of prognosis studies in systematic reviews. Ann Intern Med. 2006;144(6):427-37.

11. Fagerland MW, Lydersen S, Laake P. Recommended tests and confidence intervals for paired binomial proportions. Stat Med. 2014;33(16):2850-75.

12. DerSimonian $R$, Kacker $R$. Random-effects model for meta-analysis of clinical trials: an update. Contemp Clin Trials. 2007;28(2):105-14.

13. Woodward M. Epidemiology: Study Design and Data Analysis. Boca Raton: CRC Press; 2013

14. Fukuta H, Hayano J, Ishihara S, Sakata S, Ohte N, Takahashi H, Yokoya M, Toriyama T, Kawahara H, Yajima K. Prognostic value of nonlinear heart rate 
dynamics in hemodialysis patients with coronary artery disease. Kidney Int 2003;64(2):641-8.

15. Hayano J, Takahashi H, Toriyama T, Mukai S, Okada A, Sakata S, Yamada A, Ohte $\mathrm{N}$, Kawahara $\mathrm{H}$. Prognostic value of heart rate variability during long-term follow-up in chronic haemodialysis patients with end-stage renal disease. Nephrol Dial Transplant. 1999;14(6):1480-8.

16. Li Z, Liu S, Liang X, Wang W, Fei H, Hu P, Chen Y, Xu L, Li R, Shi W. Pulmonary hypertension as an independent predictor of cardiovascular mortality and events in hemodialysis patients. Int Urol Nephrol. 2014;46(1):141-9.

17. Matsue Y, Suzuki M, Nagahori W, Ohno M, Matsumura A, Hashimoto Y. Beta-blocker prevents sudden cardiac death in patients with hemodialysis. Int J Cardiol. 2013;165(3):519-22.

18. Matsumoto $Y$, Mori Y, Kageyama S, Arihara K, Sugiyama T, Ohmura H, Yakushigawa T, Sugiyama H, Shimada Y, Nojima Y. Spironolactone reduces cardiovascular and cerebrovascular morbidity and mortality in hemodialysis patients. J Am Coll Cardiol. 2014;63(6):528-36.

19. Moroi M, Tamaki N, Nishimura M, Haze K, Nishimura T, Kusano E, Akiba T, Sugimoto T, Hase H, Hara K. Association between abnormal myocardial fatty acid metabolism and cardiac-derived death among patients undergoing hemodialysis: results from a cohort study in Japan. Am J Kidney Dis. 2013;61(3):466-75

20. Nakamura S, Ogata C, Aihara N, Sasaki O, Yoshihara F, Nakahama H, Inenaga T, Kimura G, Kawano Y. QTc dispersion in haemodialysis patients with cardiac complications. Nephrology. 2005;10(2):113-8.

21. Nishimura M, Tsukamoto K, Tamaki N, Kikuchi K, Iwamoto N, Ono T. Risk stratification for cardiac death in hemodialysis patients without obstructive coronary artery disease. Kidney Int. 2011;79(3):363-71.

22. Ohsawa M, Tanno K, Itai K, Kato K, Fujishima Y, Onoda T, Okayama A, Sakata K, Fujioka T. Abstract P204: insufficient sleeping time was associated with a high risk for sudden cardiac death and excessive sleeping time was associated with a high risk for cerebrovascular death among hemodialysis patients. Circulation. 2012;125(10 Supplement):AP204.

23. Shoji T, Shinohara K, Kimoto E, Emoto M, Tahara H, Koyama H, Inaba M, Fukumoto S, Ishimura E, Miki T. Lower risk for cardiovascular mortality in oral 1a-hydroxy vitamin D3 users in a haemodialysis population. Nephrol Dial Transplant. 2004;19(1):179-84.

24. Takahashi H, Ishii H, Aoyama T, Kamoi D, Kasuga H, Ito Y, Yasuda K, Tanaka M, Yoshikawa D, Maruyama S. Association of cardiac valvular calcifications and C-reactive protein with cardiovascular mortality in incident hemodialysis patients: a Japanese cohort study. Am J Kidney Dis. 2013;61(2):254-61.

25. Cohn PF, Fox KM, Daly C. Review: Clinical Cardiology: New Frontiers. Silent Myocardial Ischemia. Circulation. 2003;108(10):1263-77.

26. Terazawa S, Tajima K, Takami Y, Tanaka K, Okada N, Usui A, Ueda Y. Early and late outcomes of coronary artery bypass surgery versus percutaneous coronary intervention with drug-eluting stents for dialysis patients. J Card Surg. 2012;27(3):281-7.

27. Wang AY-M, Lam CW-K, Chan IH-S, Wang M, Lui S-F, Sanderson JE. Sudden cardiac death in End-stage renal disease patients a 5-year prospective analysis. Hypertension. 2010;56(2):210-6.

28. Amabile N, Guérin AP, Tedgui A, Boulanger CM, London GM. Predictive value of circulating endothelial microparticles for cardiovascular mortality in end-stage renal failure: a pilot study. Nephrol Dial Transplant. 2012;27(5): 1873-80.

29. Blacher J, Safar ME, Guerin AP, Pannier B, Marchais SJ, London GM. Aortic pulse wave velocity index and mortality in end-stage renal disease. Kidney Int. 2003;63(5):1852-60.

30. Cashion AK, Holmes SL, Arheart KL, Acchiardo SR, Hathaway DK. Heart rate variability and mortality in patients with end stage renal disease. Nephrol Nurs J. 2005:32(2):173-88.

31. de Bie MK, Koopman MG, Gaasbeek A, Dekker FW, Maan AC, Swenne CA, Scherptong RW, van Dessel PF, Wilde AA, Schalij MJ. Incremental prognostic value of an abnormal baseline spatial QRS-T angle in chronic dialysis patients. Europace. 2013;15(2):290-6.

32. Drechsler C, Ritz E, Tomaschitz A, Pilz S, Schönfeld S, Blouin K, Bidlingmaier M, Hammer F, Krane V, März W. Aldosterone and cortisol affect the risk of sudden cardiac death in haemodialysis patients. Eur Heart J. 2012;34:578-87.

33. Drechsler C, Verduijn M, Pilz S, Dekker FW, Krediet RT, Ritz E, Wanner C, Boeschoten EW, Brandenburg V, Group NS. Vitamin D status and clinical outcomes in incident dialysis patients: results from the NECOSAD study. Nephrol Dial Transplant. 2011;26(3):1024-32.
34. Genovesi S, Rossi E, Nava M, Riva H, De Franceschi S, Fabbrini P, Viganò MR, Pieruzzi F, Stella A, Valsecchi MG. A case series of chronic haemodialysis patients: mortality, sudden death, and QT interval. Europace. 2013;15(7):1025-33.

35. Genovesi S, Valsecchi MG, Rossi E, Pogliani D, Acquistapace I, De Cristofaro V, Stella A, Vincenti A. Sudden death and associated factors in a historical cohort of chronic haemodialysis patients. Nephrol Dial Transplant. 2009;24(8):2529-36.

36. Iliou MC, Fumeron C, Benoit MO, Tuppin P, Calonge VM, Moatti N, Buisson C, Jacquot C. Prognostic value of cardiac markers in ESRD: Chronic Hemodialysis and New Cardiac Markers Evaluation (CHANCE) study. Am J Kidney Dis. 2003:42(3):513-23.

37. Johansson M, Gao SA, Friberg P, Annerstedt M, Carlström J, Ivarsson T, Jensen G, Ljungman S, Mathillas Ö, Nielsen FD. Baroreflex effectiveness index and baroreflex sensitivity predict all-cause mortality and sudden death in hypertensive patients with chronic renal failure. J Hypertens. 2007;25(1):163-8.

38. Kircelli F, Asci G, Yilmaz M, Sevinc Ok E, Sezis Demirci M, Toz H, Akcicek F, Ok E, Ozkahya M. The impact of strict volume control strategy on patient survival and technique failure in peritoneal dialysis patients. Blood Purif. 2011;32(1):30-7.

39. Koch M, Thomas B, Tschöpe W, Ritz E. Survival and predictors of death in dialysed diabetic patients. Diabetologia. 1993;36(10):1113-7.

40. Paoletti E, Specchia C, Di Maio G, Bellino D, Damasio B, Cassottana P, Cannella G. The worsening of left ventricular hypertrophy is the strongest predictor of sudden cardiac death in haemodialysis patients: a 10 year survey. Nephrol Dial Transplant. 2004;19(7):1829-34.

41. Ritz E, Strumpf C, Katz F, Wing A, Quellhorst E. Hypertension and cardiovascular risk factors in hemodialyzed diabetic patients. Hypertension. 1985;7(6 Pt 2):I11 18.

42. Vázquez E, Sánchez-Perales C, Garcia-Garcia F, García-Cortés MJ, Torres J, Borrego F, Salas D, Liébana A, Fernandez-Guerrero JC. Sudden death in incident dialysis patients. Am J Nephrol. 2014;39(4):331-6.

43. Voroneanu L, Siriopol D, Nistor I, Apetrii M, Hogas S, Onofriescu M, Covic A. Superior predictive value for NTproBNP compared with high sensitivity CTnT in dialysis patients: a pilot prospective observational study. Kidney Blood Press Res. 2014;39(6):636-47.

44. Zoccali C, Benedetto FA, Mallamaci F, Tripepi G, Giacone G, Cataliotti A, Seminara G, Stancanelli B, Malatino LS. Prognostic impact of the indexation of left ventricular mass in patients undergoing dialysis. J Am Soc Nephrol. 2001;12(12):2768-74

45. Alam A, Palumbo A, Mucsi I, Barré PE, Sniderman AD. Elevated troponin I levels but not low grade chronic inflammation is associated with cardiac-specific mortality in stable hemodialysis patients. BMC Nephrol. 2013;14(1):247.

46. Beaubien ER, Pylypchuk GB, Akhtar J, Biem HJ. Value of corrected QT interval dispersion in identifying patients initiating dialysis at increased risk of total and cardiovascular mortality. Am J Kidney Dis. 2002;39(4):834-42.

47. Foley RN, Parfrey PS, Harnett JD, Kent GM, Martin CJ, Murray DC, Barre PE. Clinical and echocardiographic disease in patients starting end-stage renal disease therapy. Kidney Int. 1995;47(1):186-92.

48. Ganesh SK, Stack AG, Levin NW, Hulbert-Shearon T, Port FK. Association of elevated serum $\mathrm{PO} 4, \mathrm{Ca} \times \mathrm{PO} 4$ product, and parathyroid hormone with cardiac mortality risk in chronic hemodialysis patients. J Am Soc Nephrol. 2001;12(10):2131-8.

49. Kruzan R, Parekh R, Herzog C, Powe N, Coresh J, Shafi T. Association of Troponin I and NT-PRO-BNP with outpatient sudden cardiac death in hemodialysis patients. In: American Journal of Kidney Diseases: 2014. Philadelphia: WB Saunders Co-Elsevier INC; 2014. p. A69-9.

50. Parekh RS, Plantinga LC, Kao WL, Meoni LA, Jaar BG, Fink NE, Powe NR, Coresh J, Klag MJ. The association of sudden cardiac death with inflammation and other traditional risk factors. Kidney Int. 2008;74(10):1335-42.

51. Scialla JJ, Plantinga LC, Kao WL, Jaar B, Powe NR, Parekh RS. Soluble P-selectin levels are associated with cardiovascular mortality and sudden cardiac death in male dialysis patients. Am J Nephrol. 2011;33(3):224-30.

52. Tangri N, Shastri S, Tighiouart H, Beck GJ, Cheung AK, Eknoyan G, Sarnak MJ. $\beta$-Blockers for prevention of sudden cardiac death in patients on hemodialysis: a propensity score analysis of the HEMO Study. Am J Kidney Dis. 2011;58(6):939-45.

53. Krishnasamy R, Badve SV, Hawley CM, McDonald SP, Boudville N, Brown FG, Polkinghorne KR, Bannister KM, Wiggins KJ, Clayton P. Daily variation in death in patients treated by long-term dialysis: comparison of in-center hemodialysis to peritoneal and home hemodialysis. Am J Kidney Dis. 2013;61(1):96-103.

54. De Lima JJ, Gowdak LH, de Paula FJ, Arantes RL, César LA, Ramires JA, Krieger EM. Unexplained sudden death in patients on the waiting list for renal transplantation. Nephrol Dial Transplant. 2011;26(4):1392-96. 
55. De Lima J, Sesso R, Abensur H, Lopes H, Giorgi M, Krieger E, Pileggi F. Predictors of mortality in long-term haemodialysis patients with a low prevalence of comorbid conditions. Nephrol Dial Transplant. 1995;10(9):1708-13.

56. Jadoul M, Thumma J, Fuller DS, Tentori F, Li Y, Morgenstern H, Mendelssohn D, Tomo T, Ethier J, Port F. Modifiable practices associated with sudden death among hemodialysis patients in the Dialysis Outcomes and Practice Patterns Study. Clin J Am Soc Nephrol. 2012;7(5):765-74.

57. Koch M, Thomas B, Tschöpe W, Ritz E. Survival and predictors of death in dialysed diabetic patients. Diabetologia. 1993;36(10):1113-17.

58. Kong MH, Fonarow GC, Peterson ED, Curtis AB, Hernandez AF, Sanders GD, Thomas KL, Hayes DL, Al-Khatib SM. Systematic review of the incidence of sudden cardiac death in the United States. J Am Coll Cardiol. 2011;57(7):794-801.

59. System USRD: Annual Data Report - Chapter 4 Cardiovascular Disease USRDS Coordinating Center 2013

60. McDonald S, Excell L, Livingston B: 33rd Annual Report- 2010 Report. ANZDATA 2010

61. Jouven X, Desnos M, Guerot C, Ducimetière P. Predicting sudden death in the population the Paris Prospective Study I. Circulation. 1999;99(15):1978-83.

62. Karnik JA, Young BS, Lew NL, Herget M, Dubinsky C, Lazarus JM, Chertow GM Cardiac arrest and sudden death in dialysis units. Kidney Int. 2001;60(1):350-7.

\section{Submit your next manuscript to BioMed Central} and we will help you at every step:

- We accept pre-submission inquiries

- Our selector tool helps you to find the most relevant journal

- We provide round the clock customer support

- Convenient online submission

- Thorough peer review

- Inclusion in PubMed and all major indexing services

- Maximum visibility for your research

Submit your manuscript at www.biomedcentral.com/submit 